ISSN 0258-7122 (Print), 2408-8293 (Online)

Bangladesh J. Agril. Res. 41(3): 461-470, September 2016

\title{
DIVERSITY OF INSECT PESTS AND NATURAL ENEMIES AS INFLUENCED BY GROWTH STAGES AND PEST MANAGEMENT PRACTICES IN RICE
}

\author{
M. A. BAKAR ${ }^{1}$ AND M. M. H. KHAN ${ }^{2}$
}

\begin{abstract}
In order to measure the diversity of insect pests and natural enemies in rice ecosystem, the present study was conducted in the research farm of Patuakhali Science and Technology University, Dumki, Patuakhali during the period from January to June, 2012 in boro rice season. Diversity indices of insect pests and their natural enemies were found to be affected by the combined effect of rice growth stages and management practices. Diversity indices of insect pests and their natural enemies differed according to treatments and crop growth stages. In case of insect pests, the untreated control treatment showed the highest diversity index (1.67) at maximum tillering stage and spray (Bipolar 55EC @ $10 \mathrm{ml} / 10 \mathrm{~L}$ of water) + perching at early tillering stage also showed highest richness (26.14) and the highest evenness (0.921) in spray at seedling stage. The highest reciprocal form of Berger-Parker's Dominance index (D) was found in untreated control at maximum tillering stage (3.03) for insect pests. In case of natural enemies, perching showed the highest diversity index (1.88) at reproductive stage. Spraying of insecticide at early tillering stage also showed highest richness (5.06) and the highest evenness (0.982) was in perching at seedling stage. The highest D value was found in perching at reproductive stage (4.67) for natural enemies.
\end{abstract}

Keywords: Diversity, growth stage, insect pest, natural enemies, pest management practices

\section{Introduction}

Rice is the most important source of the food energy for more than half of the global human population. Rice is grown in 114 countries across the world on an area about 150 million hectares with annual production of over 525 million tons, constituting nearly 11 percent of the world's cultivated land (Rai, 2006). In Bangladesh, about $90 \%$ of the population depends on rice as their major food (DAE, 2011). Rice contributes $91.1 \%$ of the total grain production and covers $74 \%$ of the total calorie intake for the people of Bangladesh (MOA, 2001). Rice is cultivated in about 11534 thousand ha land and total annual production is 33542 thousand M. tons, with an average of $2907 \mathrm{~kg} \mathrm{ha}^{-1}$ in Bangladesh (BBS, 2011).

\footnotetext{
${ }^{1 \& 2}$ Department of Entomology, Patuakhali Science and Technology University, Dumki, Patuakhali-8602, Bangladesh.
} 
Rice is grown round the year in Bangladesh and so, rice is an ideal host for many insect pest species. So far, 266 species of insect have been recorded as rice pests, of these 42 species are economically important in Bangladesh (Islam et al., 2003). The estimated annual loss of rice in Bangladesh due to insect pests and diseases amounts 1.5 to 2.0 million tons (Siddique, 1992). As some of major insect pests are considered very devastating to rice plants, they need to be controlled in the field. The main pest management method in Bangladesh is application of synthetic chemical pesticides. However, the application of chemical pesticides has got many limitations and create undesirable side effects, reduce the biological control efficacy, resulting in resurgence (Heinrichs, 1994), insecticide resistance and environmental hazard (Yoo et al., 1997; Campiche et al., 2006).

In Bangladesh, rice fields are strictly monoculture, and the lack of ecological diversity could be the major cause of insect pest problems because the food, hosts, prey and hibernating or over wintering sites of most of the natural enemies are reduced, thereby limiting natural biological control. According to Root's enemies hypothesis (Root, 1973), general and special natural enemies are expected to be more abundant in polycultures and therefore suppress herbivore population densities more than in monocultures. Both general and special natural enemies should be more abundant in polycultures than monocultures because, more pollen and nectar resources are available throughout the season in polycultures than monocultures (Root, 1973; Topham and Beardsley, 1975). Anbalagan and Narayanasamy (1999) reported that population abundance and species diversity of the spiders were directly related to the growth stages of the rice plant. Khan and Alam (2007) also reported that the diversity indices, species richness and equitability of insect pests and natural enemies were affected by the combined effect of management practices and rice growth stages. Considering the above facts the present study was undertaken to measure the diversity of insect pests and their natural enemies at different growth stages of rice in boro season

\section{Materials and Method}

The present study was conducted in research farm of Patuakhali Science and Technology University, Dumki, Patuakhali to measure the diversity of insect pests and their natural enemies in rice ecosystem. The study was done in the month of January to June, 2012 during boro rice season. Different management practices viz., spray (Bipolar 55 EC @ 10ml per 10 liter of water), perching, spray (Bipolar 55 EC @ 10ml per 10 litre of water) + perching and untreated control were applied in rice field of BRRI Dhan 29 rice variety. The whole experimental field was divided into four equal plots $(8 \mathrm{~m} \times 5 \mathrm{~m})$ as per number of treatments with $1.0 \mathrm{~m}$ distance between the plots. All treatments were applied once in each growth stage of rice plant. Only water was sprayed for untreated 
control plot. Data on insect pest and their natural enemies were collected after 7 days of treatment application. The insect pests of rice and their natural enemies were collected by a fine nylon cloth sweep net $(30 \mathrm{~cm}$ diameter). Sweeping was done from the plant canopy level including the interspaces between plants as well as close to basal region of the plants as far as possible. In each field, 10 complete sweeps were made to collect the insect pests and their natural enemies at each date of sampling at 15 days intervals. Sampling was done at four growing stages of rice viz. seedling, early tillering, maximum tillering and panicle initiation stages in boro season. Two samplings were taken at each growth stage of rice plant. Sampling was done during morning hours at all study fields on all sampling dates. The insect pests and natural enemies of 10 sweeps from each field were collected separately in labeled container. The collected samples were properly sorted, counted, identified and preserved in the laboratory of the Department of Entomology. The samples were sorted and identified under stereoscopic microscope and magnifying glass.

Diversity reflects two common components: species richness and species evenness or equitability. Diversity indices attempt to combine both components. With some further thought it becomes clear that the relative abundance of each species is related to diversity. There are measures of species richness, and there measures of relative abundance (also called "evenness" or "dominance"), and there are mixtures of both (De Jong, 1975). Interpreting measures of diversity can get complicated, and different mathematical measures have different sensitivities and bias. For the present experiment, the following indices were used to measure diversity of insect pests and their natural enemies and all the diversity indices were calculated from the original data.

\section{Species diversity}

Menzies et al. (1973) defined diversity as a community ecological concept which refers to the heterogeneity (or lack of it) in a community or assemblage of different organisms. Thus diversity is dependent upon the number of species present (Species richness, S) and the distribution of all individuals among the species (Equitability or Evenness). Indices to measure diversity are so numerous that confusion is rampant (Sanders, 1968; Whittaker, 1972; Fager, 1972; Hurlbert, 1971, Pielou, 1975). Generally a decrease in diversity is expected with pollution impact. To provide an overview of diversity, the Shannon-Weaver index of Diversity $(\mathrm{H})$ was calculated (Shannon and Weaver, 1963). The index is expressed as-

$$
H=-\sum_{i=1}^{S T} P i \log \mathrm{Pi}
$$

Where,

$\mathrm{Pi}=$ the proportion of individual $i$ th species

$\mathrm{ST}=$ the total species 


$$
\begin{aligned}
& {\left[\mathrm{Pi}=\frac{n i}{n} ; \mathrm{ni}=\right.\text { the number of individuals observed for each species }} \\
& \mathrm{N}=\text { the total number of individuals in each study area }]
\end{aligned}
$$

This index is based on 'information' theory, where diversity is equated to the amount of uncertainty which exists as to the identity of an individual collected at random from a community. The more species and the more evenly representation of individuals, the greater the uncertainty and hence the greater the diversity.

\section{Species richness}

Although a variety of indices to estimate species richness are available, none, except the actual number of species collected (S), are widely used. To provide a cohesive overview of species richness, Margalef's Index was also calculated along with $\mathrm{S}$.

Margalef's index of richness (MI) (Margalef, 1958) assumes a theoretical relationship between the number of individuals $(\mathrm{N})$ and the number of species $(\mathrm{S})$ in a sample and is expressed as follows:

$$
\text { M. I. }=\frac{S-1}{\log e N}
$$

The index logarithmically scales the value of $\mathrm{S}$, and hence provides a means of comparison between stations with different ratios of $\mathrm{S}$ and $\mathrm{N}$.

\section{Equitability or Evenness}

Equitability is considered a component of diversity, in that it provides an idea about the evenness of species distribution at a site. Usually a positive correlation exists between diversity and equitability (De Jong, 1975) i.e. a high equitability would indicate a high diversity and probably, a 'healthy condition' of a fauna. Reduction of equitability almost occurs with an increase in oligomixity. Pielou's (1966) evenness index $\left(\mathrm{J}^{\prime}\right)$ method of measuring equitability is most widely used.

The computational formula is:

$$
\mathrm{J}^{\prime}=\frac{H}{\log e S}
$$

Where,

$$
\begin{aligned}
& \mathrm{H}=\text { Shanon's index } \\
& \mathrm{S}=\text { Total species collected }
\end{aligned}
$$

The index value ranges from 0 to 1 , with a value of 1 being the maximum possible evenness in the community. 


\section{Reciprocal form of Berger-Parker's Dominance index}

Another diversity index was calculated using the Berger-Parker's Dominance Index (d) The reciprocal form of Berger-Parker's Dominance index i.e., (1/d) indicates an increase diversity and reduction in dominance (Margurran, 1988). Berger-Parker's dominance index (Berger and Parker, 1970) is expressed as:

$\mathrm{d}=\frac{N_{M A X}}{N_{T}}$

Where,

Nmax $=$ the total no. of individuals of the most abundant species

$\mathrm{N}_{\mathrm{T}}=$ Total no. of individuals of all species collected

Hence, the reciprocal form of the index is,

$\mathrm{D}=1 / \mathrm{d}$

Where,

$\mathrm{d}=$ Berger-Parker's Dominance index (Southwood, 1978).

\section{Results and discussion}

Since measures of diversity involve a number of indices, analyses and interpretation should rationally be interpolated back to the original numerical data. Several diversity indices used to measure the diversity of insect pests and natural enemies in different crop growth stages and different treatments. Shannon and Weaver (1963) diversity index (H), Pielou's (1966) evenness index (J') and Margalef's (1958) index of richness (M.I.) was calculated from the original data. Results of diversity indices are given below:

\section{Diversity of insect pests and natural enemies at different growth stages of boro rice}

Early tillering stage showed higher diversity in terms of diversity index (1.48) compared to other three stages (Table 1). But evenness was also highest in same stage (0.826) indicating the highest equability among insect pests in that stage. Richness index was highest at early tillering stage (18.51) and lowest at maximum tillering stage (10.55). The values of $\mathrm{D}$ also differed within different stage and appeared as the highest at early tillering stage (2.42) and lowest at reproductive stage (1.08). However, 4 diversity indices viz., diversity index (H), Richness (M.I.), Evenness (J) and D were found highest at early tillering stage thus seemed to be more stable than other. 
Table 1. Diversity indices, richness, evenness and equitability of insect pests community recorded by sweeping net at different stages of rice crop

\begin{tabular}{l|c|c|c|c}
\hline \multicolumn{1}{c|}{ Stages } & $\begin{array}{c}\text { Shannon diversity } \\
\text { index }(\mathrm{H})\end{array}$ & $\begin{array}{c}\text { Richness } \\
(\mathrm{M} . \mathrm{I} .)\end{array}$ & $\begin{array}{c}\text { Evenness } \\
(\mathrm{J})\end{array}$ & $\mathrm{D}$ \\
\hline Seedling stage & 1.27 & 13.5 & 0.789 & 1.89 \\
Early tillering stage & 1.48 & 18.51 & 0.826 & 2.42 \\
Maximum tillering stage & 1.26 & 10.55 & 0.703 & 1.73 \\
Reproductive stage & 0.386 & 13.12 & 0.215 & 1.08 \\
\hline
\end{tabular}

Table 2 indicates the diversity indices of natural enemies in boro rice at different stages. Diversity index (H), Evenness $(\mathrm{J})$ and $\mathrm{D}$ were found highest at seedling stage $(1.64,0.916$ and 3.57 , respectively) and the lowest at early tillering stage (1.46, 0.815 and 2.12 , respectively). This indicates that in boro rice, the diversity of insects was highest at early tillering stage due to low diversity of natural enemies.

Table 2. Diversity indices, richness, evenness and equitability of natural enemies community recorded by sweeping net at different stages

\begin{tabular}{l|c|c|c|c}
\hline \multicolumn{1}{c|}{ Stages } & $\begin{array}{c}\text { Shannon diversity } \\
\text { index (H) }\end{array}$ & $\begin{array}{c}\text { Richness } \\
(\text { M.I. })\end{array}$ & $\begin{array}{c}\text { Evenness } \\
(\mathrm{J})\end{array}$ & $\mathrm{D}$ \\
\hline Seedling stage & 1.64 & 9.89 & 0.916 & 3.57 \\
Early tillering stage & 1.46 & 9.41 & 0.815 & 2.12 \\
Maximum tillering stage & 1.5 & 11.16 & 0.837 & 2.79 \\
Reproductive stage & 1.54 & 11.23 & 0.859 & 2.5 \\
\hline
\end{tabular}

$\mathrm{D}=$ Reciprocal form of Berger Parker's dominance index

\section{Diversity of insect pests and natural enemies in different stages influenced by management practices}

Table 3 indicates diversity indices of insect pests and their natural enemies at different growth stages under different treatments. The diversity index showed higher in untreated control at maximum tillering stage (1.67) and the lowest was recorded in spray + perching treatment at reproductive stage (0.882). In richness, the highest value was found in spray + perching treatment at early tillering stage (26.14) while in perching treatment at maximum tillering stage showed the lowest richness value (9.04). In case of evenness, with spray of Bipolar 55EC @ $10 \mathrm{ml} / 10 \mathrm{~L}$ of water at seedling stage showed the highest evenness value $(0.921)$ and spray + perching treatment at reproductive stage was found the lowest value of evenness $(0.548)$ followed by untreated control at same stage $(0.598)$. In case of equitability, the highest value showed in untreated control at maximum tillering stage (3.03) and lowest in spray + perching treatment at reproductive stage (1.34). 
Table 3 also indicates diversity indices of insect pests and their natural enemies at different growth stages under different treatments. The diversity index was found highest in perching treatment at reproductive stage (1.88) followed by untreated control at maximum tillering stage (1.87) and the lowest was recorded in spray + perching treatment at maximum tillering stage (1.19). In richness, the highest value was found in the treatment of spraying of Bipolar 55EC @ 10 $\mathrm{ml} / 10 \mathrm{~L}$ of water at early tillering stage (34.79) while spray + perching treatment at maximum tillering stage showed the lowest richness value (3.87). In case of evenness, perching treatment at seedling stages showed the highest evenness value (0.982) and spray + perching treatment at maximum tillering stage showed the lowest value of evenness (0.739). In case of equitability, the highest value was observed in perching treatment at reproductive stage (4.67) and lowest in spray + perching treatment at maximum tillering stage (2.11).

Table 3. Diversity indices, richness, evenness and $D$ value of insect pests and natural enemies recorded by sweeping net at different growth stages of rice influenced by management practices

\begin{tabular}{|c|c|c|c|c|c|c|c|c|c|}
\hline \multirow[b]{2}{*}{ Stages } & \multirow[b]{2}{*}{ Treatment } & \multicolumn{2}{|c|}{$\begin{array}{l}\text { Diversity } \\
\text { index }(H)\end{array}$} & \multicolumn{2}{|c|}{$\begin{array}{l}\text { Richness } \\
\text { (M.I.) }\end{array}$} & \multicolumn{2}{|c|}{$\begin{array}{l}\text { Evenness } \\
(\mathrm{J})\end{array}$} & \\
\hline & & Pests & $\begin{array}{l}\text { Natural } \\
\text { enemies }\end{array}$ & Pests & \begin{tabular}{|l|} 
Natural \\
enemies
\end{tabular} & Pests & $\begin{array}{l}\text { Natural } \\
\text { enemies }\end{array}$ & Pests & $\begin{array}{l}\text { Natural } \\
\text { enemies }\end{array}$ \\
\hline \multirow{4}{*}{$\begin{array}{l}\text { Seedling } \\
\text { stage }\end{array}$} & Spray & 1.651 & 1.68 & 15.35 & 21.37 & 0.921 & 0.938 & 2.79 & 3.18 \\
\hline & Perching & 1.506 & 1.76 & 14.42 & 14.75 & 0.84 & 0.982 & 2.23 & 4.36 \\
\hline & $\begin{array}{l}\text { Spray + } \\
\text { Perching }\end{array}$ & 1.62 & 1.67 & 17.2 & 21.3 & 0.904 & 0.932 & 2.5 & 3.55 \\
\hline & Control & 1.42 & 1.73 & 14.97 & 15.72 & 0.792 & 0.965 & 2.04 & 3.83 \\
\hline \multirow{4}{*}{$\begin{array}{l}\text { Early } \\
\text { tillering } \\
\text { stage }\end{array}$} & Spray & 1.55 & 1.82 & 18.63 & 34.79 & 0.865 & 0.935 & 2.25 & 3.67 \\
\hline & Perching & 1.49 & 1.78 & 15.26 & 26.02 & 0.832 & 0.915 & 2.06 & 3.4 \\
\hline & $\begin{array}{c}\text { Spray + } \\
\text { Perching }\end{array}$ & 1.36 & & 26.14 & & 0.759 & 0.909 & 1.83 & 3.0 \\
\hline & Control & 1.42 & 1.82 & 10.75 & 29.01 & 0.792 & 0.935 & 2.0 & 4.09 \\
\hline \multirow{4}{*}{$\begin{array}{c}\text { Maximum } \\
\text { tillering } \\
\text { stage }\end{array}$} & Spray & 1.48 & 1.77 & 18.93 & 34.67 & 0.826 & 0.909 & 2.17 & 3.43 \\
\hline & Perching & 1.32 & 1.83 & 9.04 & 33.07 & 0.82 & 0.94 & 2.05 & 3.78 \\
\hline & $\begin{array}{c}\text { Spray + } \\
\text { Perching }\end{array}$ & 1.39 & 1.19 & 23.59 & 3.87 & 0.776 & 0.739 & 2.0 & 2.11 \\
\hline & Control & 1.67 & 1.87 & 19.1 & 22.9 & 0.858 & 0.96 & 3.03 & 4.5 \\
\hline \multirow{4}{*}{$\begin{array}{l}\text { Reproductive } \\
\text { stage }\end{array}$} & Spray & 1.05 & 1.78 & 16.95 & 31.81 & 0.652 & 0.915 & 1.5 & 3.86 \\
\hline & Perching & 1.25 & 1.88 & 16.39 & 25.56 & 0.697 & 0.966 & 1.68 & 4.67 \\
\hline & $\begin{array}{c}\text { Spray + } \\
\text { Perching }\end{array}$ & 0.882 & 1.71 & 13.04 & 25.6 & 0.548 & 0.954 & 1.34 & 3.43 \\
\hline & Control & 0.962 & 1.82 & 13.3 & 23.07 & 0.598 & 0.935 & 1.45 & 3.93 \\
\hline
\end{tabular}

$\mathrm{D}=$ Reciprocal form of Berger Parker's dominance index. 
These results are agreed with Hurlbert et al. (1989) who studied the diversity of the arthropod communities in paddy fields and found that the numbers of species and individuals, and the values of the diversities and evenness were distinctly different according to habitat, type of field and growth stage of the rice. This result also agreed with the findings of Khan and Alam (2007) where they reported that diversity indices of insect pests and natural enemies were found to be affected by the combined effect of management practices and growth stages of rice plant. Rahman et al. (2004) found that the abundance of insect pest and natural enemies was influenced by different growth stages of rice plant. They observed that the highest abundance was at reproductive stage and lowest was at mid tillering stage. Population abundance and species diversity of the spiders were found directly related to the growth stages of the rice plant. They also found that transplanted rice fields are richer both in species diversity and species richness.

\section{Conclusion}

Diversity indices of insect pests and natural enemies differed according to treatments and crop growth stages. In case of insect pests, untreated control showed the highest diversity index at maximum tillering stage and spray + perching at early tillering stage also showed highest richness and the highest evenness in spraying of Bipolar 55EC at seedling stage. The highest reciprocal form of Berger-Parker's Dominance index (D) was found in untreated control at maximum tillering stage for insect pests. In case of natural enemies, Perching showed the highest diversity index at reproductive stage and spraying of Bipolar $55 \mathrm{EC}$ at early tillering stage also showed highest richness and the highest evenness in perching at seedling stage. The highest $\mathrm{D}$ value was found in perching at reproductive stage for natural enemies. If we create better environment for natural enemies by using non-chemical control methods like perching and applying less toxic insecticides at different growth stages of rice, then greater number of natural enemies may suppress pest populations which may bring benefits to the farmers. The findings of the present study may be helpful in developing components of Integrated Pest Management (IPM) program through ecological pest management practices.

\section{References}

Anbalagan, G. and P. Narayanasamy. 1999. Population fluctuation of spiders in the rice ecosystem of Tamil Nadu. Entomol.24 (1): 91-95.

BBS (Bangladesh Bureau of Statistics). 2011. Statistics Pocket Book of Bangladesh (2010-11). Bangladesh Bureau of Statistics Division, Govt. of the People's Republic of Bangladesh. p. 206.

Berger, W. H. and F. L. Parker. 1970. Diversity of planktonic Foraminifera in deep sea sediments. Science 168: 1345-7. 
Campiche, S., K. P. Slooten, C. Ridreau and J. Tarradellas. 2006. Effects of insect growth regulators on the non-targets oil arthropod Folsomia candida (Collembola). Ecotoxicology and Environment Safe. 63: 216-225.

DAE (Department of Agricultural Extension). 2011. Krishi Dairy 2011. Published by Agriculture Information Service, Kharmarbari, Dhaka. Pp. 214.

De Jong, T. M. 1975. A comparison of three diversity indices based on their components of richness and evenness. Oikvs, 26 (2): 222-227.

Fager, E. W. 1972. Diversity: A sampling study. Amer. Nat. 106: 293-310.

Heinrichs, E. A. 1994. Host plant resistance. In: Heinrichs, E. A. (Ed.), Biology and Management of Rice insects. Wiley, New York, Pp. 517-547.

Hurlbert, S. H. 1971. The non-concept of species diversity: a critique and alternative parameters. Ecol. 52: 577-585.

Hurlbert, S. H., E. C. Shannon-Wienner, Pielou, M. S. You and Z. F. Wu. 1989. The diversity of arthropod comminutes in paddy fields. J. Fujuan hopper, Agril. College. 18 (4): 532-538.

Islam, Z., M. A. Rahman, A. T. Barrison, A. Polaszek, T. Chancellor, K. L. Heong, N. Ahmed, M. Haq and N. Q. Kamal. 2003. Diversity of arthropods in irrigated rice in Bangladesh. Bangladesh Journal of Entomology. 13(2): 1-25.

Khan, M. M. H. and M. I. Alam. 2007. Influence of management practices and growth stages of rice on the abundance and diversity of insect pests and natural enemies. Ann. Bangladesh Agric. 11(2): 21-32.

Margalef, R. 1958. Information theory in ecology. Gen. Sys. 3:36-71.

Margurran, A. E. 1988. Ecological diversity and its measurement. Princeton University Press, Princeton (New Jersey). 210p.

Menzies, R. J., R. Y. George and G. T. Rowe. 1973. Abyssal environment and ecology of the world oceans. John Wiley and Sons, New York. 488p.

MOA (Ministry of Agriculture). 2001. Bangladesh Food and Agriculture. World Food Summit., 13-17 Nov. Rome, Italy. 7.

Pielou, E.C. 1975. Ecological diversity. Wiley Intersci. 165p.

Pielou, E. C. 1966. The measurement of diversity in different types of biological collections. J. Theor. Biol. 13: 131-144.

Rahman, M. A. , M. M. H. Khan, M. F. Hasan and M. M. Alam. 2004. Incidence and abundance of insect pests and their natural enemies at different growth stages of rice. J. Agric. Educ. Technol. 7(1 and 2): 19-24.

Rai, M. 2006. Rice the cereal that feeds billions. Indian Farm. 56(7): 4-9.

Root, R. B. 1973. Organization of a plant arthropod association in simple and diverse habitats: The fauna of Colards (Brassica oleracea). Ecol. Mongr. 43:95-124.

Sanders, H. L. 1968. Marine benthic diversity: A compatible study : Amer. Nat. 102: $243-$ 282. 
Shannon, C. E. and W. Weaver. 1963. The mathematical theory of communication. Univ. Press, Urbane. $117 \mathrm{p}$.

Siddique, A. K. M. T. 1992. An overview of the ETL of rice pests and IPM scope in the content of rice production. In Proc. of the workshop on experiences with modern rice cultivation in Bangladesh. BRRI, Gazipur, pp.33 -45 .

Topham, M. and J. W. Jr. Beardsley. 1975. Influence of nectar source plants on the New Guinea sugarcane weevil parasite, Lixophaga sphenophori (Villeneuve). Proc. Hawaii. Entomol. Soc. 22:145-54.

Whittaker, R. H. 1972. Evaluation and measurement of species diversity. Toxon. 21: 213 251.

Yoo, J. K., M. H. Park, B. R. Choi, S. G. Lee and Y. J. Ahn. 1997. Resistance monitoring and cross-resistance of brown planthopper (Homoptera: Delphacidae), Nilaparvata lugens Stal in Korea. Korea Journal of Pest Science. 1: 41-47. 